\title{
Parapneumonic effusions secondary to community-acquired bacterial pneumonia in human immunodeficiency virus-infected patients
}

\author{
V. Gil Suay, P.J. Cordero, E. Martínez, J.J. Soler, \\ M. Perpiñá, J.V. Greses, J. Sanchis
}

Parapneumonic effusions secondary to community-acquired bacterial pneumonia in human immunodeficiency virus-infected patients. V. Gil Suay, P.J. Cordero, E. Martínez, J.J. Soler, M. Perpiñá, J.V. Greses, J. Sanchis. @ERS Journals Ltd 1995.

ABSTRACT: The purpose of this study was to determine whether the clinical and microbiological characteristics of parapneumonic effusions in patients with community-acquired pneumonia (CAP) infected with the human immunodeficiency virus (HIV) were different from those observed in patients without HIV infection. One hundred and thirty seven patients with parapneumonic effusions were included and divided into two groups depending on whether they had HIV infection or not.

The parapneumonic effusion rate was significantly higher in HIV-positive than in noninfected patients $(21$ vs $13 \%)$. Their clinical course was more severe, presenting a higher rate of bacteraemias (58 vs 18\%). Pleural fluid in patients infected with HIV had significantly lower glucose levels than that of patients without HIV infection. Chest tube drainage was more frequent in parapneumonic effusions of patients infected with HIV than in those without HIV infection (71 vs 44\%). Staphylococcus aureus was the most common microorganism found in the bacteriological samples of patients with CAP infected with HIV (53 vs 12\%).

We conclude that patients with community-acquired pneumonia and HIV infection have a higher rate of parapneumonic effusions and a more severe clinical course than non-HIV patients, and that Staphylococcus aureus predominates in their bacteriological samples.

Eur Respir J., 1995, 8, 1934-1939. Hospital Universitari "La Fe", Servicio de
Neumología. Valencia, Spain.

Correspondence: V. Gil Suay

Servicio de Neumología

Hospital Universitari La Fe

Avda. Campanar 21

Valencia

Spain

Keywords: Acquired immunodeficiency syndrome

bacterial pneumonia

empyema

parapneumonic effusion

pleural effusion

pleurisy

Received: August 191994

Accepted after revision August 151995
Pleural effusion is often found in patients infected with human immunodeficiency virus (HIV). In in-patients infected with HIV the frequency of pleural effusion ranges $24-27 \%$, and it is most often secondary to bacterial pneumonia or hypoalbuminaemia $[1,2]$. When secondary to bacterial pneumonia, pleural effusion occurs in the early stages of HIV infection, in association with hypoalbuminaemia it is usually associated with other diseases and/or malnutrition and often appears at more advanced stages of the disease. It is also known that patients with HIV infection are prone to develop bacterial pneumonia, and therefore its incidence is higher in this group than in the general population [1,3-6]. Although their clinical course is more severe and they often have bacteraemia, the mortality rate is rather low because these patients usually show a fast response to antibiotic therapy [7,8]. Nevertheless, little is known about the characteristics of parapneumonic pleural effusions (PPE) in HIV-positive patients.

The purpose of this study was to assess the rate of PPE among bacterial pneumonia patients infected with HIV, and to ascertain whether the clinical course, laboratory and microbiological findings of these PPE differ from those without HIV infection. The study group was made up of the patients with community-acquired pneumonia (CAP) admitted to our hospital during the last 5 years.

\section{Material and methods}

\section{Study subjects}

The medical records of patients with PPE secondary to CAP treated at our hospital from 1987 to 1992 were retrospectively reviewed. This study was carried out in a tertiary care centre with 1,200 beds serving a population of 500,000 inhabitants. Case reports were selected using a computerized search of the diagnosis codified at hospital discharge.

The PPE diagnosis was made when patients met the following criteria: acute febrile illness, purulent sputum and an infiltrate on the chest radiographic film, with concomitant occurrence of pleural effusion [9]. All patients with a diagnosis of systemic acidosis and/or initial carcinoma were excluded from the study. Patients with 
pleural effusions defined as a transudate [10], or with non-neutrophilic exudates, were also excluded. In addition, patients in whom a chest tube was inserted for reasons other than the previously described criteria based on pleural fluid analysis, e.g. because of a pneumothorax complicating thoracentesis, were not considered for the study. Tuberculosis was ruled out when sputum, pleural fluid, and/or bronchoalveolar lavage smears and cultures were negative for mycobacteria. Pulmonary embolism was excluded when, in appropriate cases, lung scans and contrast venograms were normal.

The diagnosis of HIV infection was based on the detection of antibodies to HIV by enzyme-linked immunosorbant assay (ELISA) and Western blot testing. All patients with epidemiological risk factors for HIV infection underwent these tests. Patients were divided into two groups depending on whether they had HIV infection or not. None of the HIV-positive patients in this study fulfilled the 1987 criteria of the Center for Disease Control (CDC) [11] or the collaborative centre of the World Health Organization (WHO) in Europe [12] for acquired immunodeficiency syndrome (AIDS).

\section{Data collection}

In all patients, we evaluated the gross characteristics of pleural fluid, $\mathrm{pH}$, glucose, proteins, lactate dehydrogenase (LDH), cholesterol, and their corresponding pleura/serum ratios. The differential cell count, Gram's staining, pleural fluid cultures, and the amount of fluid removed by thoracentesis or by chest tube drainage (CTD) were also assessed.

PPE was classified into one of the following subgroups according to pleural fluid characteristics: 1) empyema, defined by the presence of frank pus in the first thoracentesis; 2) complicated PPE, defined by the occurrence of nonpurulent pleural fluid with $\mathrm{pH}<7.20$, glucose $<40$ $\mathrm{mg} \cdot \mathrm{dL}^{-1}$, and Gram's stain and/or pleural fluid culture positive; and 3) noncomplicated PPE, when pleural fluid was nonpurulent with $\mathrm{pH}>7.20$, glucose $>40 \mathrm{mg} \cdot \mathrm{dL}^{-1}$ and both Gram's stain and pleural fluid culture were negative. CTD was placed in all empyemas and when the clinical evolution with antibiotic therapy was not successful.

The following epidemiological and clinical variables were evaluated in all the patients: age, sex, predisposing factors, symptoms and differential leucocyte count at admission. Blood cultures were assessed when these studies were available. Community-acquired bacteraemia was defined as a positive blood culture drawn within $24 \mathrm{~h}$ of the patient's arrival at the hospital. Microorganisms were accepted as false pathogens if they met the following criteria [13]: 1) in the blood or pleural fluid cultures a common skin organism grew on less than two occasions; 2) their physician believed that the microorganism was a skin contaminant; and 3) the lack of antibiotic treatment for them resulted in nonclinical impairment. Serological testing was performed in an initial serum sample taken from 110 patients, which included indirect immunofluorescence to serotypes $1-6$ of Legionella pneumophila, indirect immunofluorescence to Coxiella burnetti, and complement fixation to Mycoplasma pneumoniae, Chlamydia psittaci, and Influenza virus. Since diagnosis became apparent in most of the patients, we obtained serum samples in the convalescent phase in only 28 of the 110 patients. A fourfold rise in titre in paired samples or a single titre for Legionella of $\geq 56$ was accepted as evidence of infection. When legionellosis was suspected, direct immunofluorescence tests for Legionella pneumophila serogroups 1-6 and L. micdadei were performed in sputum samples, and cultured in BCYE-alpha medium.

The size of the pleural effusion was determined by the level of the meniscus on the posteroanterior (PA) chest radiographic film. "Small" pleural effusions were defined as those that did not extend above the dome of the hemidiaphragm. "Moderate" effusions were defined as those that extended above the dome of the hemidiaphragm but remained below the level of the hilum. "Large" effusions were those extending above the level of the hilum, and "massive" effusions meant complete opacification of the involved hemithorax [14]. Evidence of loculation was determined by ultrasonography, computed tomography scan and/or radiography in lateral decubitus position. The extent of parenchymal involvement was assessed by the number of lobules involved.

The various factors included in the clinical course evaluated were: the duration of symptoms from their onset until hospitalization; the duration of fever from the time of admission to hospital; the time elapsed up to leucocyte normalization; the number of antibiotics per patient; the duration of intravenous antibiotic therapy; the length of hospitalization; and the CTD requirement, decortications performed and number of deaths.

\section{Statistical analysis}

Statistical analysis was performed by applying the Mann-Whitney U-test to compare quantitative variables, and the Chi-squared test with Yates correction and, when needed, the Fisher exact test, to compare qualitative variables. Data were expressed as mean \pm standard deviation (SD); and p-values of less than 0.05 were considered statistically significant.

\section{Results}

\section{Description of patient population}

During the study, 983 patients were diagnosed as CAP, and $91(9 \%)$ of them had HIV infection. Of the 225 patients with PPE, 88 (78 patients without and 10 with HIV infection) were excluded for the following reasons: 34 medical records (six HIV-infected patients) were incomplete or not available; 22 subjects (three infected with HIV) had a concomitant neoplastic disease; six had systemic acidosis; 20 PPE were not neutrophilic; three fulfilled transudate criteria; and in three patients (one infected with HIV) a pneumothorax appeared after 
Table 1. - Characteristics of patients with parapneumonic effusion with and without HIV infection

\begin{tabular}{|c|c|c|c|}
\hline & $\begin{array}{l}\text { HIV } \\
n=21\end{array}$ & $\begin{array}{c}\text { Non-HIV } \\
n=116\end{array}$ & p-value \\
\hline Age $y{ }^{\S}$ & $29 \pm 8$ & $53 \pm 8$ & $<0.05$ \\
\hline Sex $\mathrm{M} / \mathrm{F}$ & $13 / 8$ & $81 / 35$ & NS \\
\hline Smoking & $16(76)$ & $61(53)$ & NS \\
\hline Alcoholism & $8(38)$ & $34(29)$ & NS \\
\hline Parenteral drug abuse & $18(85)$ & $1(1)$ & $<0.001$ \\
\hline Diabetes mellitus & $0(0)$ & $9(8)$ & NS \\
\hline Duration of symptoms before hospitalization days ${ }^{\S}$ & $23 \pm 32$ & $7 \pm 7$ & $<0.05$ \\
\hline Initial maximum temperature ${ }^{\circ} \mathrm{C} \S$ & $39.3 \pm 0.7$ & $38.6 \pm 0.8$ & $<0.001$ \\
\hline Chest pain & $18(86)$ & $94(81)$ & NS \\
\hline Cough & $15(71)$ & $83(72)$ & NS \\
\hline Haemoptysis & $3(14)$ & $14(12)$ & NS \\
\hline Dyspnoea & $7(33)$ & $48(41)$ & NS \\
\hline WBC cells $\cdot \mathrm{mm}^{-3 \S}$ & $11293 \pm 6010$ & $15196 \pm 6700$ & $<0.05$ \\
\hline Neutrophils ${ }^{\S}$ & $8803 \pm 5637$ & $11864 \pm 6097$ & $<0.05$ \\
\hline Lymphocytes $^{\S}$ & $1564 \pm 692$ & $1910 \pm 1161$ & NS \\
\hline CD4+ cells $(n=13)^{\S}$ & $250 \pm 150$ & - & \\
\hline \multicolumn{4}{|l|}{ Size of effusion: } \\
\hline Small & $4(19)$ & $42(36)$ & NS \\
\hline Moderate & $10(48)$ & $51(44)$ & NS \\
\hline Large & $6(28)$ & $14(12)$ & NS \\
\hline Massive & $1(5)$ & $9(8)$ & NS \\
\hline Loculated pleural effusion & $14(67)$ & $59(51)$ & NS \\
\hline Lobes involved $\$$ & $1.2 \pm 0.6$ & $1.4 \pm 0.9$ & NS \\
\hline
\end{tabular}

$\S$ : mean \pm SD. Values in parentheses are percentages. NS: nonsignificant; HIV: human immunodeficiency virus; M: male; F: female; WBC: white blood cell (count).

thoracentesis. Therefore, the 137 PPE subjects included had no other alternative cause for pulmonary infiltrates or PPE. Twenty one patients $(15 \% ; 13$ males and eight females; mean age $29 \pm 8$ yrs) were infected with HIV; 18 of these reported a history of parenteral drug abuse (PDA), one was a homosexual, and two had been contaminated by blood transfusions. The remaining 116 patients (85\%; 81 males and 35 females; mean age $54 \pm 18$ yrs) had no HIV infection. The rate of PPE among CAP patients was significantly higher in HIV-positive patients ( 21 of 99 , i.e. $21 \%$ ) than in non-HIV-infected patients $(116$ of 884 , i.e. $13 \%)(\mathrm{p}<0.05)$.

The characteristics of both groups are shown in table 1. PDA was more common among HIV-positive patients. No differences in either the remaining predisposing factors or the symptoms were found, although the peak fever and time elapsing from the onset of the symptoms until hospitalization was longer in the HIV-positive group. Leucocytes and absolute neutrophil counts in peripheral blood were significantly higher $(\mathrm{p}<0.05)$ in the group without HIV infection. Mean CD4+ lymphocyte count in HIV-positive patients was 250 cells $\cdot \mathrm{mm}^{-3}$, and five patients (none of whom had had pneumonia during the preceding 12 months) had a CD4+ lymphocyte count below 200 cells $\cdot \mathrm{mm}^{-3}$. No significant differences were found between the two groups in the other parameters studied.

In the group of patients infected with HIV we found: five empyemas, 10 complicated PPE and six noncomplicated PPE versus 29 empyemas, 25 complicated PPE and 62 noncomplicated PPE in the group without HIV infection. On admission to hospital, complicated PPE
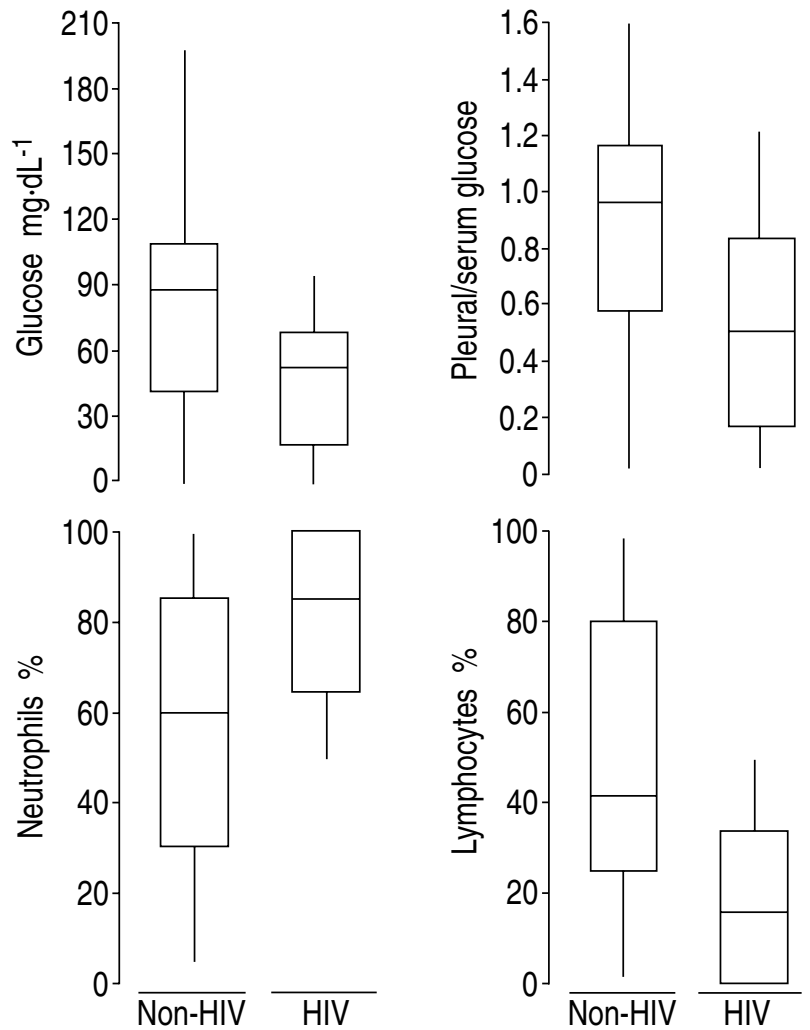

Fig. 1. - Box plots of the distributions of glucose levels, pleura/serum glucose ratio and percentage of neutrophils and lymphocytes in pleural fluid of patients with and without human immunodeficiency virus (HIV) infection. The box represents the middle $50 \%$ of the data, whereas the horizontal line inside the box is the median value of the distribution of different variables. 
was the most common form in HIV-positive patients and its frequency was significantly higher than in the general population.

\section{Pleural fluid findings}

Figure 1 presents box plots of the main cellular and biochemical parameters of pleural fluid. Significant differences were found between the glucose levels of the HIV-positive group $\left(47 \pm 33 \mathrm{mg} \cdot \mathrm{dL}^{-1}\right)$ and the patients without HIV infection $\left(84 \pm 50 \mathrm{mg} \cdot \mathrm{dL}^{-1}\right)(\mathrm{p}=0.01)$, and in the pleura/serum glucose ratio $(0.49 \pm 0.36$ versus $0.86 \pm$ $0.45 ; \mathrm{p}=0.006$ ). No differences were found between the two groups with respect to the absolute number of cells, $\mathrm{pH}$, lactate dehydrogenase, proteins and cholesterol of the pleural fluid. However, patients infected with HIV showed a significantly higher proportion of neutrophils $(81 \pm 19$ versus $58 \pm 30 \%$ in the HIV negative group; $\mathrm{p}=0.05)$

Table. 2. - Bacteriological results

\begin{tabular}{|c|c|c|c|}
\hline & HIV & Non-HIV & p-value \\
\hline Bacteria isolated & $17 / 21(81)$ & $57 / 116(49)$ & $<0.05$ \\
\hline In blood culture & $11 / 19(58)$ & $17 / 96 \quad(18)$ & $<0.001$ \\
\hline In pleural fluid & $10 / 21(48)$ & $38 / 99 \quad(38)$ & NS \\
\hline Mixed flora & 10/17 (59) & $24 / 57 \quad(42)$ & NS \\
\hline \multicolumn{4}{|c|}{ Number of patients with isolates } \\
\hline Gram-positive bacteria & 16/17 (94) & $44 / 57$ & NS \\
\hline Streptococcus & $9 / 17(53)$ & $22 / 57 \quad(47)$ & NS \\
\hline Staphylococcus & $13 / 17(76)$ & $17 / 57 \quad(30)$ & $<0.01$ \\
\hline Gram-negative bacteria & $3 / 17$ (18) & $10 / 57 \quad(17)$ & NS \\
\hline Anaerobes & $2 / 17(12)$ & $14 / 57 \quad(25)$ & NS \\
\hline
\end{tabular}

Values in parentheses are percentages. NS: nonsignificant; HIV: human immunodeficiency virus. and a smaller proportion of lymphocytes in pleural fluid (18 \pm 19 versus $49 \pm 32 \%$; $\mathrm{p}<0.01$ ).

\section{Microbiology}

Microorganisms were isolated more frequently from blood and/or pleural fluid cultures in patients with HIV infection $(\mathrm{p}<0.05)$ (table 2). The rate of subjects presenting bacteraemia was significantly higher in HIVpositive subjects than in those without HIV infection $(\mathrm{p}<0.001)$. Staphylococcal infection was significantly more common in the HIV-positive group than in patients without HIV infection $(\mathrm{p}<0.01)$. Table 3 shows the microorganisms isolated from blood and pleural fluid cultures. $S$. aureus was the microorganism most often isolated in the HIV subjects, who showed a significantly higher rate than the patients without HIV infection (9 out of 17 versus 7 out of 57 ; $\mathrm{p}<0.01$ ). None of the patients who underwent acute and convalescent serological testing for Legionella pneumophila, Coxiella burnetti, Mycoplasma pneumoniae, Chlamydia psittaci, and Influenza virus, showed evidence of seroconversion or a single titre of $\geq 256$. Sputum cultures and direct immunofluorescence tests for Legionella were performed in 54 patients and all the cases were negative for this microorganism.

\section{Clinical course}

In the group of HIV-positive patients, the duration of fever, the number of antibiotics, the duration of intravenous antibiotic treatment and the number of patients who required chest tube drainage were significantly higher than in the group of patients without HIV infection. No differences were found between the two groups with respect to the number of decortications or deaths (table 4).

Table 3. - Microorganism isolated from pleural fluid and blood cultures

\begin{tabular}{lcccc}
\hline & \multicolumn{2}{c}{ HIV } & \multicolumn{3}{c}{ Non-HIV } \\
& Pleural fluid & Blood culture & Pleural fluid & Blood culture \\
\hline Streptococcus pneumoniae & 4 & 2 & 14 & 6 \\
Streptococcus pyogenes & 1 & - & 3 & - \\
Streptococcus group C & - & - & 1 & - \\
Streptococcus group F & 1 & - & 2 & - \\
Streptococcus viridans & - & - & 1 & 1 \\
Staphylococcus aureus & 4 & 6 & 3 & 6 \\
Staphylococcus epidermidis & - & 3 & 6 & - \\
Staphylococcus saprophyticus & 1 & - & - & 2 \\
Corynebacterium sp. & - & - & - & - \\
Propionibacterium sp. & - & - & 1 & - \\
Proteus vulgaris & - & - & 1 & - \\
Pseudomonas aeuroginosa & 1 & - & 5 & - \\
Haemophilus influenzae & 1 & - & 1 & - \\
Escherichia coli & 1 & - & 1 & - \\
Serratia marcescens & - & - & 2 & - \\
Klebsiella pneumoniae & - & - & 2 & - \\
Enterobacter sp. & - & - & 2 & - \\
Bacteroides fragilis & - & - & 10 & - \\
Peptostreptococcus sp. & 1 & - & 4 & - \\
Fusobacterium sp. & - & - & 1 & - \\
Clostridium perfringens & - & - & - & - \\
Streptobacillus sp. & 1 & - & - & - \\
\hline
\end{tabular}

HIV: human immunodeficiency virus. 
Table 4. - Clinical course of patients with parapneumonic effusion with and without HIV infection

\begin{tabular}{|c|c|c|c|}
\hline & HIV & Non-HIV & p-value \\
\hline Duration of fever days ${ }^{\S}$ & $27 \pm 37$ & $9 \pm 9$ & $<0.01$ \\
\hline Elevated serum WBC days $\S$ & $14 \pm 16$ & $14 \pm 13$ & NS \\
\hline Antibiotics per patient ${ }^{\S} \mathrm{n}$ & $2.5 \pm 1.1$ & $1.8 \pm 0.8$ & $<0.05$ \\
\hline $\begin{array}{l}\text { Duration of intravenous } \\
\text { antibiotic days§ }\end{array}$ & $17 \pm 18$ & $10 \pm 10$ & $<0.05$ \\
\hline Chest tube drainage $n$ & $15 / 21(71)$ & $51(44)$ & $<0.05$ \\
\hline $\begin{array}{l}\text { Duration of chest tube } \\
\text { drainage§ days }\end{array}$ & $9 \pm 7$ & $10 \pm 8$ & NS \\
\hline Amount of pleural fluid $\mathrm{mL}^{\S}$ & $515 \pm 565$ & $566 \pm 774$ & NS \\
\hline $\begin{array}{l}\text { Duration of hospitalization } \\
\text { days }{ }^{\S}\end{array}$ & $41 \pm 40$ & $30 \pm 16$ & NS \\
\hline Decortication $\mathrm{n}$ & $1 / 21(5)$ & $5(4)$ & NS \\
\hline Death $n$ & $1 / 21(5)$ & $2(2)$ & NS \\
\hline
\end{tabular}

$\S:$ mean \pm SD. Values in parentheses are percentages. For abbreviations see legend to table 1 .

\section{Discussion}

In this study, we found that HIV-positive patients with CAP show a higher PPE rate than patients without HIV infection. Patients with PPE and HIV infection were also characterized by a more severe clinical course, a lower pleural glucose level, a higher rate of bacteraemia and positive pleural cultures and a greater need for CTD than non-HIV-infected patients.

HIV-positive patients show greater susceptibility to bacterial pneumonia than the general population [3] with a more severe clinical evolution and a higher rate of bacteraemia than the noninfected population [7, 15, 16]. PPE is not an uncommon complication of bacterial pneumonia, and its frequency depends largely on its causative microorganism [17]. It could be presumed that bacterial pneumonia complications, such as PPE, are not uncommon in these patients. Our study confirmed this fact, since a higher rate of PPE was found among patients infected with HIV.

Pleural fluid in HIV-positive patients had lower glucose levels and pleura/serum glucose ratios, which indicates greater inflammatory or bacterial activity [18]. This may be due both to the longer evolution of the disease before hospitalization in HIV-infected individuals and to the more aggressive microorganisms involved in this pathogeny (higher rate of staphyloccocal infection than in the general population). PPE patients infected with HIV showed lower levels of leucocytosis and neutrophilia in peripheral blood. However, a significantly higher proportion of neutrophils in pleural fluid suggests an effective recruitment of these cells in the pleural cavity. Although a decrease in the chemotactic response of the neutrophils and monocytes in HIV-positive patients has been reported [19-21], these alterations occur when the disease is more advanced [22] than in our patients, whose proportion of neutrophils in pleural fluid can therefore be increased.

Several studies have reported that the proportion of HIV-positive patients who presented bacteraemia in the course of a bacterial pneumonia reached $60 \%$, whilst it was $15-30 \%$ in noninfected subjects [23]. Our results also confirm this finding in HIV patients with PPE. Moreover, the level of $S$. aureus isolated from the samples of HIV-positive subjects was also significantly higher than in HIV-negative patients. There are several reasons for this. Firstly, it has recently been reported [24-26] that $S$. aureus is the microorganism which most often causes bacteraemia in HIV-positive patients. Secondly, $S$. aureus is responsible for the largest number of deaths from pneumonia in autopsy series [27, 28]. Nevertheless, in almost all studies, HIV-positive patients with $S$. aureus bacteraemia showed other risk factors, such as neutropenia, steroid therapy, Pneumocystis carinii pneumonia, Kaposi's sarcoma, PDA, lymphatic obstruction and/or presence of venous catheters [7, 25, 29-32]. In our study, all the patients with $S$. aureus infection had a history of PDA. Finally, a greater susceptibility to $S$. aureus has been observed following viral infections, such as influenza [33]. Moreover, MuRPHy et al. [34] reported that in AIDS patients the inability of neutrophils to kill $S$. aureus was not related to chemotaxis. These authors suggested that the infection of mature neutrophils by HIV may account for their reduced bactericidal capacity, favouring infection by $S$. aureus.

In our series, we did not find any cases of parapneumonic effusion for Legionella, Chlamydia or Mycoplasm. However, our study was performed on patients with pleural effusion due to community-acquired pneumonia, which could explain the discrepancies with other studies which have analysed the aetiology of community-acquired pneumonia, independent of the presence of pleural effusion. In two different studies on patients with parapneumonic effusions, Light et al. [9] and PoE et al. [35] also found no cases of these microorganisms. The reason for this is, probably, that pleural effusions secondary to these microorganisms are generally small and transient, and they do not require thoracentesis.

As in the case of HIV-positive patients with bacterial pneumonia [3], our PPE patients showed higher peak fever, longer duration of fever and were subjected to prolonged antibiotic therapy. In $71 \%$ of the cases, a CTD was needed due to the presence of complicated PPE, although there was no difference in the rate of empyemas. We think that there are two facts which may explain this: firstly, the higher rate of $S$. aureus infection in these patients, for it is known that more complications occur in PPE due to $S$. aureus than in non-Staphylococcal PPE [36]; and, secondly, the longer time between the onset of symptoms in our patients and hospitalization favours the change from an exudate to a fibrin-purulent effusion, which may require CTD [17]. Nevertheless, the number of decortications and deaths was similar to that observed in patients without HIV infection whose response to antibiotics and CDT was good.

We conclude that CAP patients infected with HIV show a higher rate of PPE than HIV-negative patients. The clinical course of PPE patients with HIV infection was more severe, with an incidence rate of complicated bacteraemia and PPE often requiring CTD. This could be due to the delayed hospitalization and/or to the predominance of $S$. aureus in bacteriological samples. Neither 
the death rate nor the number of decortications were higher in these patients. Antibiotic therapy against $S$. aureus should be included in the treatment of PPE patients infected with HIV.

Acknowledgements: The authors thank J. La Cruz for his critical review of the manuscript and F. Sanchis for obtaining information on the patients in the study.

\section{References}

1. Stover De, White Da, Romano PA, Gellene RA, Robeson WA. Spectrum of pulmonary diseases associated with the acquired immune deficiency syndrome. Am J Med 1985; 78: 429-437.

2. Joseph J, Strange C, Sahn SA. Pleural effusions in hospitalized patients with AIDS. Ann Intern Med 1993; 118 : 856-859.

3. Fels AOS. Bacterial and fungal pneumonias. In: White DA, Stover DE, eds. Pulmonary Effects of AIDS. Clin Chest Med 1988; 9: 449-457.

4. Murray JF, Felton CP, Garay SM, et al. Pulmonary complications of the acquired immunodeficiency syndrome. N Engl J Med 1984; 310: 1682-1688.

5. Magnenat JL, Nicod LP, Auckenthaler R, Junod AF. Mode of presentation and diagnosis of bacterial pneumonia in human immunodeficiency virus-infected patients. Am Rev Respir Dis 1991; 144: 917-922.

6. Witt DJ, Craven DE, McCabe WR. Bacterial infections in adult patients with the acquired immune deficiency syndrome (AIDS) and AIDS-related complex. Am J Med 1987; 82: 900-906.

7. Redd SC, Rutherford GW, Sande MA, et al. The role of human immunodeficiency virus infection in pneumococcal bacteremia in San Francisco residents. J Infect Dis 1990; 162: 1012-1017.

8. Mitchell DM, Miller RF. Recent developments in the management of the pulmonary complications of HIV disease. Thorax 1992; 47: 381-390.

9. Light RW, Girard WM, Jenkinson SG, George RB Parapneumonic effusions. Am J Med 1980; 69: 507-512.

10. Light RW, MacGregor MI, Luchsinger PC, Ball WC. Pleural effusions: the diagnostic separation of transudates and exudates. Ann Intern Med 1972; 77: 507-513.

11. Centers for Disease Control. Revision of the CDC surveillance case definition for acquired immunodeficiency syndrome. MMWR 1987; 36 (Suppl. 1-15).

12. WHO-EC Collaborating Centre on AIDS. AIDS surveillance in Europe. Quarterly Report No. 37, 1993.

13. Krumholz HM, Sande MA, Lo B. Community-acquired bacteremia in patients with acquired immunodeficiency syndrome: clinical presentation, bacteriology and outcome. Am J Med 1989; 86: 776-779.

14. Gravelyn TR, Michelson MK, Gross BH, Sitrin RG. Tetracycline pleurodesis for malignant pleural effusions. Cancer 1987; 59: 1973-1977.

15. Falcó V, Fernández de Sevilla T, Alegre J, et al. Bacterial pneumonia in HIV-infected patients: a prospective study of 68 episodes. Eur Respir J 1994; 7: 235-239.

16. Polsky B, Gold JWM, Whimbey E, et al. Bacterial pneumonia in patients with the acquired immunodeficiency syndrome. Ann Intern Med 1986; 104: 38-41.

17. Light RW. Pleural diseases. 2nd Edn. Philadelphia Lea \& Febiger, 1990; 138-142.

18. Sahn SA. The pleura. Am Rev Respir Dis 1988; 138: 184-234.
19. Valone FH, Payan DG, Abrams DI, Goetzl EJ. Defective polymorphonuclear leukocyte chemotaxis in homosexual men with persistent lymph node syndrome. J Infect Dis 1984; 150: 267-271.

20. Nielsen H, Kharazmi A, Faber V. Blood monocyte and neutrophil functions in the acquired immune deficiency syndrome. Scand J Immunol 1986; 24: 291-296.

21. Smith PD, Ohura K, Masur H, Lane HC, Fauci AS, Wahl SM. Monocyte function in the acquired immune deficiency syndrome: defective chemotaxis. J Clin Invest 1984; 74: 2121-2128.

22. Rodriguez-Barradas MC, Musher DM, Hamill RJ, Dowell M, Bagwell JT, Sanders CV. Unusual manifestations of pneumococcal infection in human immunodeficiency virus-infected individuals: the past revisited. Clin Infect Dis 1992; 14: 192-199.

23. Janoff EN, Breiman RF, Daley CL, Hopewell PC. Pneumococcal disease during HIV infection: epidemiologic, clinical and immunologic perspectives. Ann Intern Med 1992; 117: 314-324.

24. Murray JF, Garay SM, Hopewell PC, Mills J, Snider GL, Stover DE. Pulmonary complications of the acquired immunodeficiency syndrome: an update. Report of the second National Heart, Lung and Blood Institute Workshop. Am Rev Respir Dis 1987; 135: 504-509.

25. Whimbey E, Gold JWM, Polsky B, et al. Bacteremia and fungemia in patients with the acquired immunodeficiency syndrome. Ann Intern Med 1986; 104: 511-514.

26. Levine SJ, White DA, Fels AOS. The incidence and significance of Staphylococcus aureus in respiratory cultures from patients infected with the human immunodeficiency virus. Am Rev Respir Dis 1990; 141: 89-93.

27. Marchevsky A, Rosen MJ, Chrystal G, Kleinerman J. Pulmonary complications of the acquired immunodeficiency syndrome: a clinicopathologic study of 70 cases. Hum Pathol 1985; 16: 659-670.

28. Niedt GW, Schinella RA. Acquired immunodeficiency syndrome; clinicopathologic study of 56 autopsies. Arch Pathol Lab Med 1985; 109: 727-734.

29. Berman DS, Schaefler S, Simberkoff MS, Rahal JJ. Staphylococcus aureus colonization in intravenous drug abusers, dialysis patients and diabetics. J Infect Dis 1987; 155: 829-832.

30. Jacobson MA, Gellerman H, Chambers H. Staphylococcus aureus bacteremia and recurrent staphylococcal infection in patients with acquired immunodeficiency syndrome and AIDS-related complex. Am J Med 1988; 85: 172 176.

31. Armstrong D, Gold JWM, Dryjanski J, et al. Treatment of infections in patients with the acquired immunodeficiency syndrome. Ann Intern Med 1985; 103: 738-743.

32. Walzer PD, Perl DP, Krogstad DJ, Rawson PG, Schultz MG. Pneumocystis carinii pneumonia in the United States: epidemiologic, diagnostic and clinical features. Ann Intern Med 1974; 80: 83-93.

33. Kleinerman ES, Snyderman R, Daniels CA. Depressed monocyte chemotaxis during acute influenza infection. Lancet 1975; ii: 1063-1066.

34. Murphy PM, Lane HC, Fauci AS, Gallin JI. Impairment of neutrophil bactericidal capacity in patients with AIDS. J Infect Dis 1988; 158: 627-630.

35. Poe RH, Marin MG, Israel RH, Kallay MC. Utility of pleural fluid analysis in predicting tube thoracostomy/decortication in parapneumonic effusions. Chest 1991; 100: 963-967.

36. Light RW. Management of parapneumonic effusions. Chest 1991; 100: 892-893. 